\title{
Vivência clínica hospitalar: significados para enfermeiros residentes em Saúde da Família
}

\author{
Hospital clinical experience: meanings for Family Health resident nurses \\ Vivencia clínica hospitalaria: significados para enfermeros residentes en Salud de la Familia
}

\author{
Simone Alves Landim', Nildo Alves Batista', Gilberto Tadeu Reis da Silvall \\ 'Universidade Federal de São Paulo. Programa de Pós-graduação. Mestrado em Ciências da Saúde. São Paulo, SP \\ "Faculdade Santa Marcelina. São Paulo, SP
}

Submissão: 28/07/2009

Aprovação: 12/09/2010

\section{RESUMO}

Trata-se de pesquisa Qualitativa na vertente fenomenológica, almejando compreender o significado da vivência clínica hospitalar na formação do enfermeiro na Residência Multiprofissional em Saúde da Família. O estudo foi desenvolvido em uma instituição paulista de ensino superior. A coleta dos dados utilizou a entrevista, tendo, como população do estudo, oito enfermeiros residentes. Utilizou-se a seguinte Questão norteadora: "Fale de sua vivência hospitalar, como ela se mostra na sua formação enQuanto residente? Das descrições, emergiu a categoria aberta: Aproximando a vivência hospitalar e a Atenção Primária à Saúde. Dos significados atribuídos à vivência hospitalar, encontra-se sua necessidade e relevância como parte integrante do currículo da residência para os enfermeiros.

Descritores: Competência clínica; Educação em enfermagem; Internato e residência.

\section{ABSTRACT}

This Qualitative research in phenomenological design aimed at understanding the meaning of hospital clinical experience in the nurse's training in a Multiprofessional Family Health Residency. The study was developed in a teaching institution. Data collection was based on interviews and had as study population eight resident nurses. I investigated the residents' experience according to their speeches, by making the following guiding Question: "Talk about your hospital experience, how does it show itself in your training as a resident"? One open categorie emerged from the subject' description: Causing to approach the hospital experience and the Primary Health Care. Among the meanings attributed to the hospital experience, there is the need and relevance as an integrant part of the curriculum vitae of the Multiprofessional Family Health Residency for the nurses.

Key words: Clinical competence; Nursing, education; Internship and residency.

\section{RESUMEN}

Se trata de investigación cualitativa en la vertiente fenomenológica, anheló comprender el significado de la vivencia clínica hospitalaria en la formación del enfermero en la Residencia Multiprofesional en Salud de la Familia. El estudio fue desarrollado una institución de enseñanza superior. La colecta de los datos utilizó la entrevista, teniendo como población del estudio ocho enfermeros residentes. Busqué en los discursos de los residentes sus vivencias, por medio de la siguiente cuestión orientadora: "Hable de su vivencia hospitalaria, ¿cómo ella se muestra en su formación mientras residente"? De las descripciones de los sujetos, surgió uno categoría abierta: Aproximando la vivencia hospitalaria y la Atención Primaria a la Salud. De los significados atribuidos a la vivencia hospitalaria, se encuentra la necesidad y relevancia como parte integrante del currículo de la Residencia Multiprofesional en Salud de la Familia para los enfermeros. Palabras-clave: Competencia clínica; Educación en enfermería; Internato y residencia.

AUTOR CORRESPONDENTE Simone Alves Landim. Rua Cachoeira da Ilha, 66. Itaquera. CEP 082270- I I0. São Paulo, SP. E-mail: simone.landim@fasm.edu.br 


\section{INTRODUÇÃO}

A motivação para a realização deste estudo originou-se durante a trajetória profissional de um dos autores a partir de um convite para realizar atividades de preceptoria na área de enfermagem, no Programa de Pós-Graduação lato sensu, na modalidade de Residência Multiprofissional em Saúde da Família (RMSF), desenvolvida em parceria com Ministério da Saúde, Faculdade Santa Marcelina e Casa de Saúde Santa Marcelina.

A Residência Multiprofissional em Saúde foi regulamentada pela Lei $n^{\circ} 11.129$, sancionada pelo presidente da República em 30 de julho de 2005, Que instituiu a Residência em área Profissional da Saúde. No âmbito do Ministério da Educação, tem-se a Comissão Nacional de Residência Multiprofissional em Saúde. De acordo com essa lei, devem ser priorizadas as áreas de formação necessárias para atender o Sistema Único de Saúde (SUS) ${ }^{(1)}$.

Segundo levantamento realizado pela Secretária de Gestão do Trabalho e Educação na Saúde - SGTES e a Diretoria Executiva de Gestão do Ensino Superior - DEGES, os programas de Residências Multiprofissionais em Saúde, financiados pelo Ministério da Saúde, estão presentes na região Norte (Rondônia), Nordeste (Bahia, Maranhão, Pernambuco, Sergipe), Sul (Paraná, Rio Grande do Sul, Santa Catarina) e Sudeste (Minas Gerais, São Paulo) ${ }^{(2)}$.

A Residência Multiprofissional em Saúde da Família, desenvolvida pela Faculdade Santa Marcelina, tem como uma de suas principais finalidades a formação de profissionais de saúde para a Atenção Básica no SUS, na Estratégia Saúde da Família ${ }^{(3)}$.

Define como objetivo capacitar os profissionais a perceberem a multicausalidade dos processos mórbidos, sejam físicos, mentais ou sociais, tanto individuais como coletivos, contextualizando sempre o indivíduo em seu meio ambiente. Abrange as seguintes profissões: Enfermagem, Farmácia, Fisioterapia, Fonaudiologia, Medicina, Nutrição, Odontologia, Psicologia, Serviço Social e Terapia Ocupacional(3).

A carga horária era de 5.520 horas/aula e de 60 horas semanais, com duração de dois anos. Foram priorizadas as atividades na Atenção Primária à Saúde no cenário da Estratégia Saúde da Família, com o mínimo de horas em ambiente hospitalar; as atividades no âmbito hospitalar foram preconizadas para os enfermeiros e médicos ${ }^{(3)}$.

Dentre os programas de Residência Multiprofissional em Saúde da Família existentes no Brasil, a maioria privilegia a vivência hospitalar para enfermeiros, diferindo na maneira como são estruturados $^{(2)}$.

Os residentes eram supervisionados por preceptores da sua categoria profissional, de território Que fazem o acompanhamento da equipe multiprofissional nas unidades, além dos tutores de área onde são pactuadas as ações específicas e interdisciplinares ${ }^{(3)}$.

O preceptor, segundo a Portaria n ${ }^{\circ} 1.111$ de 05 de julho de 2005, desempenha função de supervisão docente-assistencial por área de atuação ou especialidade profissional, exercendo atividades de organização do processo de aprendizagem e de orientação técnica aos residentes.

A inserção da enfermagem estruturou-se a partir das exigências para programas de residências credenciadas, da dimensão teóricoprática da enfermagem, em um contexto multiprofissional com a perspectiva de colaboração e compartilhamento de saberes e práticas $^{(3)}$.
Há estudo ${ }^{(4)}$ Que menciona Que a inserção dos enfermeiros em ambiente hospitalar objetivou fortalecer o julgamento clínico, promovendo uma vivência clínica e reflexiva dos agravos à saúde, correlacionados ao perfil epidemiológico da Atenção Primária a Saúde no cenário da Estratégia Saúde da Família.

A inserção do enfermeiro residente em ambiente hospitalar foi bastante difícil, pois apesar da bagagem teórica, era notável a dificuldade para relacionar os conteúdos aprendidos com a realidade apresentada. Conseguiam descrever os agravos à saúde, porém tinham limitações para articular esse saber a uma situação real Que transcendia ao contexto fechado dos livros, exigindo, assim, a capacidade de julgar, identificar problemas e propor intervenções ${ }^{(4)}$.

As unidades hospitalares para atuação dos residentes foram determinadas a partir do perfil profissiográfico, perfil epidemiológico prevalente nas áreas da Estratégia Saúde da Família, dos dados de mortalidade e das principais causas de internações hospitalares ${ }^{(4)}$.

Partindo do pressuposto Que a Atenção Primária a Saúde é responsável pela identificação, encaminhamento e acompanhamento dos agravos a saúde após alta hospitalar, acredita-se Que vivenciar a assistência no período hospitalar proporciona aos residentes uma melhor compreensão dos agravos e o desenvolvimento de competências, principalmente o julgamento clínico.

O julgamento clínico consiste em um processo mental, norteado pelos princípios da ciência e determinado pelo conhecimento, experiência, percepção e intuição do enfermeiro Que procura fazer julgamentos com base em evidências, os Quais o levam ao diagnóstico de enfermagem, aproximando-se do conceito de competência clínica ${ }^{(5)}$.

Competência clínica pode ser entendida como a capacidade de realizar, aceitalvelmente, aQueles deveres diretamente relacionados ao cuidado de paciente; é a capacidade de agir eficazmente em uma determinada situação, com base em conhecimentos, mas sem a eles se ater, de forma a mobilizar o todo ou parte de seus recursos cognitivos e afetivos para interagir em situações complexas. Nesse sentido, os recursos devem ser mobilizados e aplicados por meio da ação profissional, em circunstâncias reais do mundo do trabalho e durante a atuação profissional ${ }^{(6)}$.

Assim, a partir do vivido, Questionou-se a influência da trajetória hospitalar na formação dos residentes enfermeiros. Pensando na participação e atuação do residente enfermeiro na Atenção Primária à Saúde e suas responsabilidades assistenciais, Que envolvem desde ações de prevenção e promoção como também reabilitação e acompanhamento dos agravos, este estudo foi realizado com o intuito de explicitar como essa experiência se mostra para aQueles Que a vivenciam. O propósito consistiu de uma aproximação ao seu pensar e, a partir de seus discursos, desvelar perspectivas dessa prática, para, então, compreendê-la. Assim, o objetivo foi compreender os significados da vivência clínica hospitalar na formação de residentes enfermeiros do Programa de Residência Multiprofissional em Saúde da Família, com vistas à sua atuação na Atenção Primária a Saúde.

\section{MÉTODO}

Ao propor a investigação no sentido de como se dá a vivência clínica hospitalar na formação do enfermeiro na Residência Multiprofissional em Saúde da Família, pensou-se em ir além do 
mundo das aparências e dos conhecimentos teóricos, buscando por uma aproximação dessa experiência humana, para apreendê-la a partir do seu mundo-vida. Por isso, optou-se pela pesquisa Qualitativa fenomenológica, cuja proposta básica fundamenta-se na compreensão daquilo Que se Quer estudar como fenômeno humano ${ }^{(7-8)}$.

A pesquisa Qualitativa segundo a abordagem fenomenológica visa à descrição da realidade e coloca, como ponto de partida, sua reflexão sobre o próprio ser humano, no esforço de encontrar o Que é dado na experiência, descrevendo "o que ocorre, efetivamente, do ponto de vista daquele Que vive determinada situação concreta" ${ }^{(9)}$.

Os sujeitos da pesquisa foram os residentes enfermeiros da Residência Multiprofissional em Saúde da Família da Faculdade Santa Marcelina- Unidade de Ensino Itaquera. A região de inquérito, lócus neste estudo, foi a vivência clínica hospitalar desses enfermeiros. O número de participantes do estudo foi sendo configurado à medida Que se realizava a análise dos dados Que emergiram das entrevistas, sendo esse número definido, portanto, pelas próprias descrições. Dessa forma, foram coletados oito discursos por meio da seguinte Questão norteadora: "Fale de sua vivência hospitalar, como ela se mostra na sua formação enQuanto residente?".

As entrevistas foram realizadas após a análise e aprovação dos Comitês de Ética em Pesquisa da Universidade Federal de São Paulo/ Hospital São Paulo - Parecer CEP no 0037 /08 e da Faculdade Santa Marcelina - Parecer no 357/08/07. Precedendo cada início da entrevista, foi lido o Termo de Consentimento Livre e Esclarecido, garantindo, dessa forma, os preceitos éticos e legais envolvidos em pesquisa com seres humanos, respeitando-se, assim, os aspectos ético-legais da Portaria 196/96, do Comitê Nacional de Pesquisas com Seres Humanos. Optou-se pela gravação das falas dos sujeitos, por proporcionar maior liberdade do pesquisador para atentar às falas originárias, penetrar o mundo dos residentes e compreender o fenômeno vivido e investigado. Foi permitido aos sujeitos participantes do estudo que falassem livremente sobre o fenômeno, não sendo estabelecido tempo de duração, com o cuidado de não interferir durante sua fala, pois, em QualQuer observação ou pergunta, poderia haver interferência no discurso espontâneo do sujeito. As entrevistas foram gravadas com as autorizações prévias e, posteriormente transcritas, com o cuidado de manter na íntegra tudo o Que foi descrito pelos residentes enfermeiros.

Após a coleta dos discursos e suas transcrições, foi realizada sua análise, Que se encontra dividida em duas etapas importantes: a análise ideográfica e a análise nomotética.

A primeira etapa, análise ideográfica, teve início com as transcrições dos discursos, Quando foi estabelecido um contato direto com o fenômeno vivido, por meio de uma leitura cautelosa de todos os discursos. Cada discurso, identificado pela letra D, foi submetido a uma re-leitura para identificação de Unidades de Significado (US), tendo sempre em mente a Questão norteadora do estudo. Por meio dessa análise, foi possível ter uma visão global do discurso, iluminando os significados encontrados. A segunda etapa, análise nomotética, é a análise da totalidade dos discursos em que ocorre o cruzamento entre as unidades de significado e uma reflexão sobre a estrutura geral do fenômeno. Neste momento, começaram a se esboçar as primeiras generalidades, apresentando os aspectos comuns entre os discursos, o Que permitiu Que o fenômeno se desvelasse.

\section{RESULTADOS E DISCUSSÃO}

Construindo caminhos a partir da compreensão do fenômeno

Ao serem interrogados sobre os significados da vivência hospitalar na sua formação, os residentes enfermeiros reviveram seu modo de ver, sentir, perceber a vivência hospitalar na sua formação e retrataram suas percepções dentro de um contexto do Que é familiar sobre esse fenômeno para eles. Ao descrever essas percepções, verbalizaram pensamentos e sentimentos relacionados a essa vivência.

Assim, neste momento, foram destacadas as convergências Que procuram/revelam o sentido Que os residentes enfermeiros entrevistados atribuem à vivência hospitalar na sua formação.

A organização dos discursos permitiu a apreensão de subtemas Que convergiram para o tema: Aproximando a vivência hospitalar e a Atenção Primária à Saúde.

\section{Tema - Aproximando a vivência hospitalar e à Atenção Primária à Saúde}

Para essa categoria aberta, convergiram as unidades de significado Que descreveram a percepção dos residentes ao vivenciarem o contexto hospitalar, como eixo para uma melhor atuação na Atenção Primária à Saúde.

Dessa maneira, para melhor compreensão do tema, encontrase ele dividido nos seguintes subtemas: Articulando o modelo assistencial-hospitalar com a Atenção Primária à Saúde; Articulação ensino/ serviço; O preceptor como articulador de saberes; Interação e diálogo entre os pares no ambiente hospitalar; Possibilidade de interação com a família.

\section{Articulando o modelo assistencial-hospitalar com a Atenção Primária à Saúde}

Quando da estruturação do currículo da residência, pensou-se na participação e atuação do residente enfermeiro no Que tange à Atenção Primária à Saúde e às responsabilidades assistenciais, Que envolvem desde ações de prevenção e promoção de saúde, como também curativas, de reabilitação e acompanhamento dos agravos.

Ao considerar as ações curativas, de reabilitação e acompanhamento dos agravos, concebe-se o domicílio como um cenário de atuação da Atenção Primária à Saúde. Sendo assim, necessário se faz preparar os enfermeiros para prestar assistência de enfermagem com Qualidade e segurança. Nesse sentido, é possível uma reflexão sobre as possibilidades da vivência hospitalar, em virtude da sintomatologia clínica, dos inúmeros procedimentos e intervenções realizados no hospital, e Que, muitas vezes, são reportados para o domicílio.

(...) então era muito interessante Quando nós voltávamos para a unidade, a gente conseguia visualizar na hora do exame físico, na consulta do paciente exatamente o que era importante e que a gente tinha aprendido na prática hospitalar. (D7US05)

O domicílio é um espaço adequado ao cuidado de enfermagem na medida em Que a contenção de despesas e os riscos de infecção servem de argumento para reduzir o período de permanência, tanto em unidades de internação como em unidades de tratamento intensivo(10) 
Dessa maneira, Questiona-se como articular o modelo assistencial-hospitalar com a Atenção Primária à Saúde. Compreende-se que os hospitais representam um importante papel Quando se pensa em construção de linhas de cuidado Que articulem diferentes equipamentos de saúde na produção das respostas às necessidades dos usuários ${ }^{(11)}$.

Nesse sentido, a vivência hospitalar favoreceu a discussão sobre a necessária articulação dos níveis de atenção à saúde em busca da integralidade da assistência. Concomitantemente, o cotidiano hospitalar proporcionou aos residentes lidarem diariamente com situações Que possibilitam o exercício de habilidades e atitudes como a flexibilidade, confiança, paciência, intuição, adaptação e o reconhecimento de suas limitações profissionais.

(...) no hospital a gente sempre enfatiza juntar; é a parte do posto com a parte do hospital, ver o paciente como um todo, ele esta ali no hospital, e assim melhorou o Quadro dele no hospital, e agora ele vai para casa, Quais são os cuidados com ele em casa, a orientação com a família; então foi muito gratificante. (D8US08)

Compreende-se a necessidade de trabalhar a formação generalista dos enfermeiros, em virtude da complexidade de suas ações na Atenção Primária à Saúde, abrangendo, em um único dia, ações de prevenção e promoção à saúde, atendimento de urgência/ emergência e as ações curativas, sejam no contexto do domicílio ou na unidade de saúde.

(...) você vê Que muitas vezes o próprio enfermeiro da unidade básica perde isso; na hora Que chega, ele não sabe atender (...), então, isso vai ficando e acaba Que o enfermeiro só faz a parte de prevenção, consultório (...) (D5US04)

Assim, é possível afirmar Que a diversificação dos cenários de aprendizagem é essencial, face aos diferentes tipos de complexidade envolvidos nos problemas de saúde, Que exigem a mobilização de diferentes áreas de saber ${ }^{(12)}$.

A fala apresentada a seguir expressa a concepção dos residentes sobre a "Articulação do modelo assistencial-hospitalar com a Atenção Primária à Saúde"

(...) então, assim, foi muito proveitoso, muito; da gente chegar em casa, refletir o que viu ali, e ir para casa ler e discutir, e eu levo muito para a unidade também; tudo, tudo que eu vi ali. (D3US06)

Evidencia-se ser possível articular o modelo assistencial-hospitalar com a Atenção Primária à Saúde, compreendendo Que a atuação clínica, com enfoQue na doença, na prescrição e no tratamento é de fundamental importância no contexto do cuidado à saúde, uma vez Que a população encontra-se adoecida. Essa articulação é viável desde que o modelo assistencial-hospitalar esteja associado a uma visão de saúde ampliada, incorporando, ao fazer profissional, competências Que possibilitem ter uma visão diferenciada, integral, ampliada do processo saúde doença ${ }^{(13)}$.

Assim, enfatiza-se a importância das discussões de forma a favorecer a articulação do modelo assistencial-hospitalar com o preventivo. Essas discussões devem ser oportunizadas a todo o momento, permeadas por experiências vivenciadas na Atenção Primária à Saúde, centradas no usuário inserido no contexto familiar e social, na perspectiva de promover o empoderamento, tanto do usuário Quanto da equipe. Essas discussões devem buscar conhecer a respeito da fisiopatologia, intervenções referentes ao processo saúde-doença, interação com o indivíduo e família, aprimorando e desenvolvendo procedimentos técnicos, urgência/emergência e julgamentos clínicos dos problemas apresentados pelos pacientes e/ou família. Ressalta-se o pensamento Freiriano, segundo o qual a ação de ensinar não é transferir conhecimentos, mas criar as possibilidades para a sua produção ou a sua construção.

\section{Articulação ensino/serviço}

Os preceptores, ao proporem a vivência hospitalar, refletiram sobre a necessidade de possibilitar a articulação ensino (teoria) e prática (serviço). Percebe-se a importância e a necessidade da colaboração/articulação entre os dois locais de formação, de modo Que a teoria tenha repercussões na prática e as práticas possam influenciar e atualizar o processo ensino/aprendizagem em uma perspectiva integral ${ }^{(14)}$.

Ao pensar em uma perspectiva integral, caminha-se ao encontro da definição de integralidade; segundo o Dicionário Houaiss, há termos que se aproximam: integral, como adjetivo (total, inteiro, global); integrar, como verbo transitivo direto (completar, inteirar, integralizar) e totalidade, como substantivo (conjunto das partes Que constituem um todo; soma).

Os sentidos da integralidade permeiam desde atributos como acesso, capacidade dos profissionais de perceber os usuários em suas dimensões biopsicossociais, articulação da equipe multiprofissional nos serviços, até oferta de serviços Que compreendam desde a promoção da saúde à reabilitação de seQuelas e a possibilidade de articulação de serviços em níveis crescentes de sofisticação tecnológica para resolução dos problemas da população(15).

O princípio de integralidade, em um dos seus sentidos, corresponde exatamente a uma crítica da dissociação entre a teoria e prática assistenciais, fomentadas por meio de distinções cristalizadas entre serviços de saúde pública e outros assistenciais ${ }^{(16)}$.

Nesse sentido, a vivência hospitalar almejou superar a dissociação entre teoria e prática, por meio da assistência integral ao cuidado do paciente, e, concomitantemente, visou integrar o contexto assistencial hospitalar com o preventivo.

Refletindo sobre a assistência e a formação, de maneira integrada, almeja-se a articulação de todos os passos na produção do cuidado e no restabelecimento da saúde, passos esses Que permeiam a associação da teoria à prática, por meio de um acompanhamento da trajetória do cuidado, evitando-se, assim, sua fragmentação e dissociação.

Dessa maneira, emerge a necessidade de desenvolvimento de um processo educacional permanente, integrando o ensino com serviços, voltado para a criação de novos valores, trabalhando mais com a saúde do Que com a doença, não priorizando apenas as ações hospitalares, curativas e individuais e Que, acima de tudo, realizem tais procedimentos por meio de uma equipe multiprofissional $^{(3)}$.

Sob esse prisma, é possível perceber os desafios vivenciados, 
na medida em Que os currículos da maioria das instituições de ensino superior de graduação em enfermagem estão direcionados a um saber fragmentado. É preciso reforçar Que o todo é a soma das partes, porém o homem e o mundo ultrapassam essas fronteiras ${ }^{(17)}$

Vejamos o discurso a seguir:

(...) logo no começo da residência nós tivemos um curso de primeiros socorros lá, mas não é a mesma coisa; não é aQuilo Que a gente Quer, não é a prática, igual na faculdade, Quando tivemos o curso de primeiros socorros, então assim a nossa necessidade é para aplicar na unidade o que a gente aprendeu, porque nunca se sabe o que vai aparecer. (D3US02)

Ao iniciar a vivência hospitalar, surge uma reflexão sobre essa formação fragmentada e o desafio de integrá-la no contexto da prática. Percebe-se Que, apesar da bagagem teórica, era notória a dificuldade em relacionar os conteúdos aprendidos à realidade apresentada.

Eles eram capazes de descrever, com base em referenciais teóricos, os agravos à saúde, porém apresentaram limitações para articular esse saber a uma situação real Que escapava ao contexto fechado dos livros, exigindo, assim, uma capacidade de julgar, identificar problemas e propor intervenções.

Nesse contexto, esta pesQuisa denota a aproximação conceitual de multidisciplinaridade, entendida pela justaposição de várias disciplinas em torno de um mesmo tema ou problema. As várias disciplinas são colocadas lado a lado, porém, sem interação, as diferentes áreas coexistem lado a lado, mas com baixíssima interrelação, corroborando com estudo realizado ${ }^{(18)}$.

Acredita-se Que essa formação seja ineficiente para preparar os profissionais para atenderem às demandas do mercado, posto Que o mercado os expõe a cenários e situações Que escapam ao seu arcabouço teórico, exigindo reflexão e julgamento clínico, dentre outros.

A partir desse contexto, a vivência hospitalar foi estruturada de maneira Que pudesse integrar teoria e prática. Para tanto, recorreuse às diretrizes curriculares nacionais, as Quais sugerem Que a formação (ensino) em áreas da saúde deve privilegiar a prática (serviço) contextualizada, ocupando lugar central na formação e estando presente em cenários diversificados ao longo de todo o curso $^{(11)}$.

Autores $^{(19)}$ corroboram a discussão ao apontarem Que, em se tratando do processo ensino-aprendizagem, um dos desafios que a enfermagem tem enfrentado diz respeito à formação de profissionais competentes Que busquem a articulação entre teoria e prática, segundo uma visão crítica acerca da realidade.

O discurso a seguir expressa essa preocupação e permite refletir sobre as possibilidades da vivência hospitalar aproximar ensino e serviço.

(...) Quando nós chegamos ao hospital com aquela sede, aquela vontade; assim muito do Que a gente viu nos livros, muito do Que a gente viu na faculdade, a gente tava vendo ali, e Que não era realidade diária, então isso traz muita satisfação prá gente viu, é muito legal, eu acho que é isso, a necessidade partiu daí mesmo. (D3US04)
Sob esta ótica, acredita-se ser importante um investimento no permanente diálogo da ação (o Que fazer) com o interlocutor (situação), segundo uma perspectiva de resolução de problemas e construção de saberes Que facilite o desenvolvimento de uma teoria articulada à prática ${ }^{(20)}$.

Dessa maneira, será possível ligar a ação à situação e estabelecer conexões entre a prática e os seus referentes teóricos, resultando em uma visão integral e contextualizada dos problemas profissionais.

Acreditando Que a assistência de enfermagem precisa ser vivenciada e Que somente a teoria não consegue proporcionar subsídios efetivos para a atuação segura e eficaz, cabe ao enfermeiro ter habilidades em todos os ciclos de vida no que se refere a agravos à saúde.

No cotidiano hospitalar, os enfermeiros assumem, em geral, o cuidado integral ao paciente, o Que envolve ações para atendimento das necessidades humanas básicas (alimentação, higiene, conforto) e as ações mais complexas, para as Quais se faz necessário um amplo conhecimento da clínica (teoria e prática) para aprimoramento de uma competência essencial ao enfermeiro: a competência clínica ou julgamento clinico.

Pensando no desenvolvimento dessa competência, posteriormente ao atendimento das necessidades humanas básicas, os residentes eram acompanhados e direcionados para a anamnese, entrevista detalhada com o paciente e a família. Nesse momento, eram identificados e apontados os pontos principais Que seriam explorados no exame físico.

O exame físico detalhado permitiu aos enfermeiros correlacionar os sinais e sintomas; para isso, havia necessidade de um ampla bagagem teórica sobre a Qual pudessem refletir e Questionar os achados levantados no exame físico (prática).

Ao correlacionarem os sinais e sintomas, eles exercitavam e aproximavam a teoria e a prática. Posteriormente a essa etapa, eram elencados os problemas evidenciados em ordem de prioridade, determinando-se os diagnósticos de enfermagem e, então, as intervenções e as implementações eram discutidas.

Com essa dinâmica diária, foi possível uma aproximação do vivido pelos residentes, possibilitando a articulação entre teoria e prática, almejando superar as limitações da formação. Nesse sentido, reafirma-se o pensamento Freiriano ${ }^{(21)}$, permitindo aos residentes a criação de um processo metodológico de construção do conhecimento, com base em sua relação com o contexto, com a realidade e com a sua cultura.

\section{O preceptor como articulador de saberes}

É essencial o papel do preceptor no sentido de favorecer a articulação do modelo assistencial-hospitalar com a Atenção Primária à Saúde. Entende-se que o desenvolvimento processa-se em interação com outras pessoas Que têm, em seu cargo, a responsabilidade de orientar a aprendizagem do residente em contextos da prática clínica.

Compreende-se Que a simples inserção do residente em ambiente hospitalar dificulta essa articulação com a Atenção Primária à Saúde. O preceptor irá mediar o aprendizado em ambiente hospitalar; nesse sentido, necessita estar envolvido com o planejamento da residência, pois, assim, poderá "apreender" do hospital aquilo que é relevante para a atuação do enfermeiro na Atenção Primária à Saúde. 
O preceptor deve estimular e auxiliar na construção do conhecimento, assumir responsabilidades em situações clínicas complexas, possibilitando uma reflexão sobre o observado e o vivido, favorecendo a construção ativa do conhecimento na ação de aprender a fazer, fazendo ${ }^{(20)}$.

Ao identificar as situações hospitalares Que melhor problema-tizam a realidade vivida na Atenção Primária à Saúde, o preceptor, assumindo a assistência de enfermagem, conjuntamente com os residentes, conseguiu desenvolver e aprimorar as competências clínicas e algumas habilidades técnicas elementares à profissão. Ele exerce a função de preceptoria entendida como uma estratégia de ensino-aprendizagem individualizada, Que busca promover a integração de conhecimentos, habilidades e atitudes desenvolvidas pelo aluno, ao longo do curso, para construir sua identidade profissional ${ }^{(23)}$.

As falas apresentadas a seguir expressam a concepção dos residentes sobre o papel do preceptor na construção do conhecimento em ambiente hospitalar.

(...) a forma Que a gente sempre discutia, com a preceptora nos momentos de discussão, como a gente pode evitar Que o paciente chegue nesse estado Quando a gente tiver na unidade (...) (D7US08)

(...) passaram pra gente essa Questão de ir para o hospital, então essa vivência, desde o começo, foi muito boa porque a gente tinha pessoas por perto pra dar essa vivência pra gente (...) (D7US02)

As falas sinalizam o papel do preceptor na aproximação da vivência hospitalar e a Atenção Primária à Saúde. Essa aproximação ocorreu por meio de discussão de caso à beira do leito , grupos de estudos sobre temas específicos e pela sistematização da assistência de enfermagem.

Cabe ressaltar Que o vínculo do preceptor com as pessoas, com o contexto hospitalar e com os residentes foi o grande facilitador dessa aproximação.

Nesse sentido, este trabalho aponta Que o sucesso ou não da aprendizagem fundamenta-se, essencialmente, na afetividade, confiança, empatia e no respeito entre residentes e preceptores, residentes e residentes, preceptores e preceptores, Questões estas também presentes em outro estudo ${ }^{(24)}$.

\section{Interação e o diálogo entre os pares no ambiente hospitalar.}

Refletindo sobre a vivência hospitalar e a interação e o diálogo entre os pares, emerge a discussão acerca de seu papel em possibilitar a interação entre os pares, compreendendo Que a plena interação entre o indivíduo, a formação e o contexto de trabalho, os processos formativos desenvolvem capacidades de resolução de problemas e de pensamento criativo ${ }^{(20)}$.

Compreende-se Que a vivência hospitalar contribui para o processo formativo dos enfermeiros, não somente pelas Questões técnicas e clínicas, como também pela possibilidade da interação com outros membros da equipe multiprofissional, favorecendo a troca e compartilhamento de novos saberes.

Vejamos o discurso a seguir:

(...), porém, a gente indo lá ficou sabendo o Quanto era importante, uma das primeiras coisas é o conjunto dos enfermeiros, você entra em contato com enfermeiros de diversas formações enquanto residentes, e lá a gente pode trocar experiências, coisa que na unidade não dá, vai um enfermeiro só e outras profissões, não é. (DIUS02)

Para os enfermeiros, a possibilidade de trocar experiências com enfermeiros de outras áreas teve um papel formativo a partir da interação Que favoreceu o desenvolvimento de novas competências. Esse componente formativo advém do diálogo, das discussões, do descobrimento de novas realidades e pontos de vista diferentes sobre determinadas temáticas envolvendo o cotidiano deste profissional.

Nesse contexto, corrobora-se com estudos ${ }^{(20)}$ Que abordam a situação de trabalho Que, pela sua complexidade e pela mobilização de competências múltiplas requeridas, pressupõe a interação de uma pessoa ou grupo e comporta, por isso, um potencial formativo.

\section{Possibilidade de interação com a família}

Dentre os desafios em aproximar a vivência hospitalar da Atenção Primária à Saúde, encontra-se o de envolver e interagir com a família em ambiente hospitalar. Compreende-se que a família é essencial na efetivação da assistência de enfermagem, não sendo possível, portanto, deixar de criar estratégias para trabalhar com a família em ambiente hospitalar.

Esse aspecto configura-se enфuanto um desafio na formação dos residentes no Programa de Residência Multiprofissional em Saúde da Família. Tal desafio advém da formação, onde as áreas das ciências da saúde sofreram influências do modelo mecanicista e cartesiano, segundo o Qual a decomposição das partes em subpartes favorecia o melhor entendimento do todo, dificultando, dessa maneira, a visão do todo e o cuidado integral.

Acredita-se Que a família constitui-se em um espaço onde se constrói saúde; no entanto, ela ainda não é concebida como uma unidade para prestação de assistência à saúde e seus membros continuam sendo vistos de maneira individualizada ${ }^{(25)}$.

Nesse sentido, é preciso resgatar o olhar sobre os indivíduos, suas famílias e seus contextos de vida, identificando a configuração e a dinâmica familiar, papéis Que desempenham e Quais são os alicerces Que foram construídos ao longo de sua trajetória, reconhecendo-as como unidade, respeitando sua autonomia e favorecendo a resolução de seus problemas ${ }^{(26)}$.

As estratégias elencadas para trabalhar com as famílias em ambiente hospitalar fundamentam-se no conceito do pensamento sistêmico, aplicado aos sistemas familiares.

Um sistema familiar é parte de um supra-sistema mais amplo, o Qual, por sua vez, é composto de muitos subsistemas; a família como um todo é maior do Que a soma das partes; a mudança em um membro da família afeta a todos; a mudança depende da percepção do problema, do contexto, dos objetivos codesenvolvidos. Todo trabalho com famílias é colaborativo, é processual e deve ocorrer por sucessivas aproximações; facilitar a mudança é papel do profissional envolvido ${ }^{(26)}$.

Ao aproximar esse contexto de família para o ambiente hospitalar, depara-se com a realidade hospitalar, onde o cuidado recebido pelo paciente é produto de um grande número de pequenos cuidados parciais, Que vão se complementando a partir da interação 
entre os diferentes profissionais Que atuam em ambientes diversos no hospital.

É um importante desafio coordenar esse conjunto diversificado, especializado, fragmentado de cuidadores individuais, de modo Que eles articulem suas práticas, aproximando a família, resultando em um cuidado integral ${ }^{(1)}$.

Propostas como a da Residência Multiprofissional Saúde da Família, ao diversificar os cenários de ensino aprendizagem, possibilitam trabalhar essas limitações em ambiente hospitalar, despertando a equipe hospitalar para essa temática.

O discurso a seguir evidencia esse aspecto:

\section{(...) a gente está no PSF, porém existe toda uma Questão familiar} na área hospitalar, muitas vezes o profissional Que está no hospital não enxerga, mas Quando a gente ta lá, a partir do PSF, a gente começa a perceber, eu tenho a percepção Que os profissionais na área hospitalar vêem a família como uma coisa Que vai atrapalhar, então é uma forma de como a gente trabalha família lá dentro influenciando a equipe. (D6US03)

Sob essa perspectiva, percebe-se a importância da atuação dos residentes enfermeiros em ambiente hospitalar, pensando em suas possibilidades de influenciar, proporcionar o diálogo e a troca com os profissionais Que atuam no hospital, no sentido de Que algumas práticas e valores sejam revistos.

O discurso a seguir exemplifica Que é possível aproximar a família ao cuidado assistencial hospitalar, reportando à Atenção Primária à Saúde:

(...) a proposta da família estar junto nos cuidados, nas explicações no dia a dia do paciente né, a gente também retomou isso na parte hospitalar, então dá para fazer um gancho do hospital com o PSF, foi muito válido, muito mesmo. (D8US09)

Essa pesquisa permitiu compreender que o paciente, muitas vezes acometido por enfermidades, poderá ter, na família, o apoio e cuidados necessários para seu restabelecimento e/ou minimização de suas sequelas. Dessa maneira, configura-se a necessidade de envolver a família nos cuidados diários em ambiente hospitalar.

\section{CONSIDERAÇÕES FINAIS}

O presente estudo teve como tema de pesQuisa a vivência clínica hospitalar do enfermeiro na Residência Multiprofissional em Saúde da Família. Almejou compreender os significados da vivência clínica hospitalar na formação do enfermeiro na Residência Multiprofissional em Saúde da Família.

Revelou, entre outros aspectos, a necessidade de integrar a vivência clínica hospitalar no currículo da residência para os enfermeiros, assim como provocou reflexão sobre os aspectos essenciais a serem abordados no hospital, com foco na Atenção Primária à Saúde, fazendo emergir o papel do preceptor como mediador do conhecimento em ambiente hospitalar.

Nesse sentido, ao refletir sobre a influência da trajetória hospitalar na formação do residente enfermeiro, os discursos revelaram um mundo a partir do olhar dos residentes sobre sua percepção da vivência hospitalar.
Com relação ao tema "Aproximando a vivência hospitalar e a Atenção Primária à Saúde", a partir das convergências dos seus discursos emergiram suas percepções sobre a vivência hospitalar e sua aproximação com a Atenção Primária à Saúde.

Percebe-se ainda Que o currículo da residência para os enfermeiros mostra a necessidade de articular o modelo assistencialhospitalar com a Atenção Primária à Saúde. Cabe ao enfermeiro a identificação, encaminhamento e acompanhamento dos agravos à saúde após alta hospitalar.

Nesse contexto, e a partir dos discursos dos residentes enfermeiros, ressalta-se a importância da articulação do modelo assistencialhospitalar com a Atenção Primária à Saúde. Essa importância advém das experiências realizadas na Atenção Primária à Saúde, onde, a partir da vivência hospitalar, sentiram-se melhor preparados para a realização da consulta de enfermagem, a execução de técnicas, a visita domiciliar e para o atendimento à urgência e emergência.

Ainda no contexto hospitalar, foi possível trabalhar a articulação ensino (teoria) e o serviço (prática). Esse aspecto é de fundamental importância e configura-se como um desafio a ser trabalhado no currículo da residência, tendo em vista o reflexo da graduação dos enfermeiros, marcada pelo excesso de disciplinas e pela aproximação tardia com os cenários da prática.

Um aspecto facilitador para essa aproximação em ambiente hospitalar, Quando se pensa em desenvolvimento de competências assistenciais, é que o paciente no hospital encontra-se adoecido, com sinais e sintomas aparentes. Esses sinais e sintomas (prática) isoladamente dizem pouca coisa, porém, Quando relacionados ao arcabouço teórico, ganham um significado a partir da interação ensino/serviço.

Para uma efetiva aproximação da teoria com a prática, os discursos sinalizaram para o papel do preceptor como articulador de saberes. O preceptor envolvido com o contexto da residência consegue planejar as atividades hospitalares Que vão ao encontro das necessidades percebidas na Atenção Primária à Saúde.

Dentre as atividades direcionadas pelo preceptor em ambiente hospitalar, encontra-se a de criar estratégias de aproximação com a equipe multiprofissional, almejando a interação e o diálogo entre os pares no ambiente hospitalar.

Das estratégias utilizadas para favorecer o diálogo e aproximação com a equipe multiprofissional, pode-se mencionar a visita para discussão de casos à beira do leito, a Qual, além de proporcionar a troca e compartilhamento dos saberes, também favorece a interação e participação da família com o processo de cuidar.

$\mathrm{Na}$ visita à beira do leito são discutidos aspectos relevantes à internação, sua evolução, prognóstico, metas a serem alcançadas e a definição dos papéis de cada membro da equipe. A partir dessa situação educativa, evidencia-se Que a vivência hospitalar, ao proporcionar o diálogo com a equipe multiprofissional e com a família, tem potencial para favorecer uma melhor atuação do enfermeiro na Atenção Primária à Saúde.

Compreende-se Que a Residência Multiprofissional em Saúde da Família, por encontrar-se em processo de construção face à sua recente proposição como modalidade de ensino, interagindo comunidade, pesquisa e ensino, vem contribuindo para a Qualificação dos profissionais do SUS, especialmente em relação à Atenção Primária à Saúde.

Mais ainda, dos significados atribuídos à vivência hospitalar, 
emerge a necessidade e a relevância da vivência clínica hospitalar como parte integrante do currículo da Residência Multiprofissional em Saúde da Família para os enfermeiros.
Almeja-se Que este estudo contribua para novas ações e intervenções sobre a vivência clínica na formação dos enfermeiros na Residência Multiprofissional em Saúde da Família.

\section{REFERÊNCIAS}

I. Ministério da Saúde (BR). I Seminário Nacional de Residência Multiprofissional em Saúde. Brasília: Ministério da Saúde; 2005.

2. Ministério da Saúde (BR). Secretaria de Gestão do trabalho e da Educação em Saúde. Departamento de Gestão da Educação em Saúde. Residência Multiprofissional em Saúde: experiências, avanços e desafios. Brasília: Ministério da Saúde; 2006.

3. Casa de Saúde Santa Marcelina. Faculdade Santa Marcelina. Projeto Político Pedagógico do Programa de Residência Multiprofissional em Saúde da Família. São Paulo: Faculdade Santa Marcelina; 2005.

4. Alves SS, Silva GTR. Como desenvolver a reflexão teóricoprática em ambiente hospitalar, reportando para o Programa de Saúde da Família em um grupo de residentes enfermeiros da Residência Multiprofissional em Saúde da Família. In: Coletânea das Semanas Científicas da Faculdade Santa Marcelina e Escola Sophia Marchetti, São Paulo (SP), Brasil. São Paulo: Faculdade Santa Marcelina; 2005. p.250-2.

5. Lima LR, Pereira SVM, Chianca TCM. Diagnósticos de Enfermagem em pacientes pós-cateterismo cardíaco: contribuição de Orem. Rev Bras Enferm 2006; 59(3): 285 90.

6. Lima V. Competência: distintas abordagens e implicações na formação de profissionais de saúde. Interface - Comum Saúde Educ 2005; 9(17): 369-79.

7. Martins J, Bicudo, MAV A pesquisa Qualitativa em psicologia: fundamentos e recursos básicos São Paulo: Editora Moraes; 1989.

8. Boemer, M.R. A condução de estudos segundo a metodologia de investigação fenomenológica. Rev Latino-am Enfermagem 1994; 2(1): 83-94.

9. Aranha MLA, Martins HPM. Filosofando: introdução à filosofia. São Paulo: Moderna; 1998

10. Lima TC, Vargas MAO. Cuidado domiciliar intensivo: uma possível realidade do Sistema Único de Saúde? Rev Bras Enferm 2004; 57(6): 658-61.

1 1. Feuerwerker LCM, Cećlio LCO. O hospital e a formação em saúde: desafios atuais. Ciênc Saúde Coletiva 2007; 12(4): 965-71.

12. Silva GTR. Preceptoria como ação educativa: uma leitura hermenêutica fenomenológica [tese]. São Paulo: Universidade Federal de São Paulo, Departamento de Enfermagem; 2003.

13. Nascimento DDG. A Residência Multiprofissional em Saúde da Família como estratégia de formação da força de trabalho para o SUS [tese]. São Paulo: Universidade de São Paulo; 2008.
14. Sá-chaves I, Alarcão I. Supervisão de professores e desenvolvimento humano: uma perspectiva ecológica. In: Formação, conhecimento e supervisão - contributos nas áreas da formação de professores e de outros profissionais. In: Sá-Chaves I, organizador. Estudos Temáticos. Aveiro: Universidade de Aveiro; 2000. p.143-59.

15. Silva IAG, Mascarenhas MT. Avaliação da atenção básica em saúde sob a ótica da integralidade aspectos conceituais e metodológicos. In: Pinheiro R, Mattos RA, organizadores. Cuidado: as fronteiras da integralidade. Rio de Janeiro: IMS/ UERI; 2004. p. 24I-57.

16. Pinheiro R, Mattos RA. Construção da integralidade: cotidiano, saberes e práticas em saúde. Rio de Janeiro: UERJ/IMS: ABRASCO; 2003.

17. Gattás MLB. Interdisciplinaridade: Formação e ação na área de saúde. Ribeirão Preto: Holos; 2006.

18. Furtado IP. Equipes de referência: arranjo institucional para potencializar a colaboração entre disciplinas e profissões. Interface: Comum Saúde Educ 2007; 1 I (22): 239-45.

19. Vale EG, Guedes MVC. Competências e habilidades no ensino de administração em enfermagem à luz das diretrizes curriculares nacionais. Rev Bras Enferm 2004; 57(4): 475-8.

20. Silva DM, Silva EMVB. O ensino clínico na formação em enfermagem. Millenium Rev ISPV 2005; 30(8): 103-8.

21 . Freire P. Pedagogia da autonomia: Saberes necessários à prática educativa. São Paulo: Paz e Terra; 1996.

22. Alçarão I, Rua M. Interdisciplinaridade, estágios clínicos e desenvolvimento de competência/ Interdiciplinarity, clinical placementes and develpmente of competences. Texto Contexto Enferm 2005; 14(03): 373-82.

23. Sanna MC, Silva GTR, Gomes PC. Programa de preceptoria do curso de graduação em Enfermagem da Faculdade Santa Marcelina. In: $51^{\circ}$ Congresso Brasileiro de Enfermagem, $10^{\circ}$ Congresso Panamericano de Enfermagem; 1999 out 2-7; Florianópolis (SC), Brasil. Florianópolis: ABEn; 1999. p. 182.

24. Lessa GM. Residência multiprofissional como experiência de atuação interdisciplinar na assistência à saúde da família. Rev Bras Enferm 2000; 53 (esp): 107-10.

25. Saupe R, Wendhausen ALP. Interdisciplinaridade e Saúde. Itajaí: Universidade do Vale do Itajaí; 2007.

26. Rodrigues CRF. Famílias como unidade do cuidado em saúde: subsídios para o ensino/prática em graduação. In: Ohara ECC, Saito RXS, organizadores. Saúde da Família: considerações teóricas e aplicabilidade. São Paulo: Martinari; 2008. p. 77-99. 